\title{
Effects of Different Solid Solution Temperatures on Microstructure and Mechanical Properties of the AA7075 Alloy After T6 Heat Treatment
}

https://doi.org/10.1515/htmp-2019-0050

Received Aug 10, 2018; accepted Feb 04, 2019

\begin{abstract}
In this study, the effect of solid solution temperature on microstructure and mechanical properties of the AA7075 alloy after T6 heat treatment was investigated. Following solid solution at five different temperatures for 2 hours, the AA7075 alloy was quenched and then artificially aged at $120^{\circ} \mathrm{C}$ for 24 hours. Hardness measurements, microstructure examinations (SEM+EDS, XRD) and tensile tests were carried out for the alloys. The results showed that the increased solid solution temperature led to formation of precipitates in the microstructures and thus caused higher hardness and tensile strength.
\end{abstract}

Keywords: AA7075 alloy, aging, solid solution, microstructure, mechanical properties

\section{Introduction}

$7 \mathrm{xxx}$ series aluminum alloys maintain their attractiveness due to their high strength and have increasing use in the aviation industry. In recent years, there seems to be a significant increase in the number of studies using different processes to further improve the strength and other properties (e.g. corrosion) of these alloys [1-3]. The most commonly preferred method to improve the strength of Al-Zn$\mathrm{Mg}-\mathrm{Cu}$ alloys is artificial aging (T6) heat treatment. Also, the strength of $7 \mathrm{xxx}$ series alloys can be improved significantly using different heat treatment processes (re-aging

\footnotetext{
^Corresponding Author: Dursun Ozyurek: Dep. of Manufacturing Engineering, Technology Faculty, Karabuk University, Karabuk, Turkey; Email: dozyurek@karabuk.edu.tr

Süleyman Tekeli: Dep. of Metallurgy and Materials Engineering, Technology Faculty, Gazi University, Ankara, Türkey Ijlal Simsek: Dep. of Machinery and Metal Technology, TOBB Technical Sciences Vocational School, Karabuk University, Karabuk, Turkey

Dogan Simsek: Dep. of Automotive Technology, Technical Sciences Vocational School, Bitlis Eren University, Bitlis, Turkey
}

O Open Access. (c) 2019 S. Tekeli et al., published by De Gruyter. (Cc) BY License
[RRA]) and high temperature pre-precipitation (HTPP) [412]. Among $7 \mathrm{xxx}$ series aluminum alloys, AA7075 is the most preferred. This alloy is used in the aerospace industry in particular due to its good mechanical properties such as high strength, ductility, and toughness. The strength of the AA7075 alloy is improved using different heat treatments. T6 heat treatment applied to this alloy is one of the most important ways that improve the mechanical properties of the alloy with both the solid solution heat treatment and the artificial aging treatment [13, 14]. T6 heat treatment is applied in three steps. The first step is the solution treatment (forming the solid solution), the second step involves the rapid cooling (forming the supersaturated structure), and the final step is the aging treatment (precipitation hardening) [15]. During the hardening of the alloy, some uncontrolled phases form in the structure. The purpose of the solution treatment is to ensure these uncontrolled phases in the structure dissolve during the hardening of the alloy. This treatment is carried out at a temperature below the eutectic temperature or in the singlephase region above the solvus curve. Once the dissolution is completed, the rapid cooling is performed to form the supersaturated solid solution structure. At this stage, a supersaturated solid solution is obtained at room temperature by rapidly cooling the structure with quenching. In the first step, the second phase $\left(\mathrm{MgZn}_{2}\right)$ precipitates are formed in the structure by applying aging heat treatment at certain temperatures for certain durations. The second phase $\left(\mathrm{MgZn}_{2}\right)$ precipitates formed in the structure by aging treatment allow for improving the strength of the material. These precipitates formed in the structure by aging depend on the degree to which uncontrolled phases that form in the structure during hardening dissolve. For this reason, this study aims to investigate changes in the microstructure and mechanical properties of the AA7075 alloy solution treated at five different solid solution temperatures after T6 heat treatment.

This work is licensed under the Creative Commons Attribution 4.0 
Table 1: The chemical composition of the AA7075 alloy used in the experimental studies.

\begin{tabular}{ccccccc}
\hline Element & $\mathbf{Z n}$ & $\mathbf{M g}$ & $\mathbf{C u}$ & $\mathbf{F e}$ & $\mathbf{C r}$ & $\mathbf{S i}$ \\
\hline \% vol. & 5.9 & 2.734 & 1.561 & 0.196 & 0.2 & 0.0117 \\
\hline Element & $\mathbf{M n}$ & $\mathbf{T i}$ & $\mathbf{V}$ & $\mathbf{Z r}$ & $\mathbf{B}$ & $\mathbf{A l}$ \\
\hline$\%$ vol. & 0.0687 & 0.0343 & 0.0066 & 0.0091 & 0.0025 & Bal. \\
\hline
\end{tabular}

\section{Materials and Method}

In the experimental studies, the AA7075 aluminum alloy that is commonly used in the sector of space and aerospace owing to its specific weight, high strength, electrical and thermal conductivities was used in the experimental studies. AA7075 alloy which is used in this study, was taken from ACA METAL Industrial firm. Chemical composition of the AA7075 alloy used in the experimental studies is given in the Table 1. The alloy to be used in the experiments was homogenized for 2 hours at $500^{\circ} \mathrm{C}$ (at a heating rate of $10^{\circ} \mathrm{C} / \mathrm{min}$ ) prior to the aging processes. Homogenized stick AA7075 aluminum alloy of $9 \mathrm{~mm}$ in diameter was treated sensitively in the turning machine and tensile samples were prepared according to ASTM: B557M-10 standards.

The alloys were solid solution treated at 5 different temperatures $\left(465^{\circ} \mathrm{C}, 470^{\circ} \mathrm{C}, 475^{\circ} \mathrm{C}, 480^{\circ} \mathrm{C}\right.$, and $\left.485^{\circ} \mathrm{C}\right)$ for 2 hours, rapidly cooled and artificially aged at $120^{\circ} \mathrm{C}$ for 24 hours. The alloys prepared by standard metallographic procedures were etched using $2 \mathrm{ml} \mathrm{HF}, 3 \mathrm{ml} \mathrm{HCI}, 20 \mathrm{ml}$ $\mathrm{HNO}_{3}, 175 \mathrm{ml} \mathrm{H}_{2} \mathrm{O}$ (Keller's) solution for 10-15 seconds. "Jeol JSM-6060" scanning electron microscope (SEM) was used for microstructure examinations and fracture surfaces. Rigaku D-Max Rint-2200 Series device was used for XRD analysis to determine phases formed in microstructure. The hardness measurements were performed using Affri hardness measurement device and the average of five measurements was taken. Tensile test were carried out using Shimadzu AG-IS ( $50 \mathrm{kN}$ ) tensile machine at cross head speed of $2 \mathrm{~mm} / \mathrm{min}$.

\section{Results and Discussion}

Figure 1 shows SEM images of the AA7075 alloy aged at $120^{\circ} \mathrm{C}$ for 24 hours following solid solution at 5 different temperatures.

SEM images given in Figure 1 show that the structure consisted of $\alpha-\mathrm{Al}, \mathrm{Al}-\mathrm{Zn}-\mathrm{Mg}$ eutectic, and micro-gaps formed in the structure. Also, $\mathrm{MgZn}_{2}$ precipitates seem to have formed in the structure after solid solution at dif-
Table 2: EDS results of the AA7075 alloy applied solid solution at $485^{\circ} \mathrm{C}$.

\begin{tabular}{cccc}
\hline Point / wt \% & Al & Mg & Zn \\
\hline $\mathbf{1}$ & 87.958 & 2.884 & 9.158 \\
$\mathbf{2}$ & 90.932 & 2.109 & 6.959 \\
$\mathbf{3}$ & 88.685 & 1.406 & 9.909 \\
\hline
\end{tabular}

ferent temperatures and aging treatment. Figure 2 shows the XRD results of the specimen after T6 heat treatment. The XRD results showed the $\mathrm{MgZn}_{2}$ precipitates in the microstructure. Second phase precipitates are the most important factors improving the strength of the alloy. It is noted in a previous study that second phases such as $\mathrm{Al}_{7} \mathrm{Cu}_{2} \mathrm{Fe}, \mathrm{Al}_{2} \mathrm{CuMg}$, and $\mathrm{MgZn}_{2}$ form in the structure of the AA7075 alloy [16]. Table 2 shows the EDS results of the AA7075 alloy applied solid solution at $485^{\circ} \mathrm{C}$. According to the EDS results, points 1 and 3 number can be seen as $\mathrm{Zn}$ rich regions.

Second phase precipitates $\left(\mathrm{MgZn}_{2}\right)$ formed in the structure after T6 heat treatment are the most important factors improving the mechanical strength of this alloy. On the other hand, intermetallic phases such as $\mathrm{Al}_{7} \mathrm{Cu}_{2} \mathrm{Fe}$ and $\mathrm{Al}_{2} \mathrm{CuMg}$ are also reported to contribute to improved strength in 7xxx series alloys in a previous study [17]. Precipitates observed in the SEM images given in Figure 1 may be attributed to these compounds. Figure 3 shows the hardness and tensile strength change of the alloy after solid solution at different temperatures followed by aging treatment.

As shown in Figure 3a, the hardness values of the alloys increased with increasing solid solution temperature. The minimum hardness value was $192 \mathrm{HV}$ for the alloy solid solution treated at $465^{\circ} \mathrm{C}$. The maximum hardness value, on the other hand, was $212 \mathrm{HV}$ for the alloy solid solution treated at $485^{\circ} \mathrm{C}$. This increase in the hardness value may be interpreted as that the dissolution process achieved its purpose by formation of precipitates with the increase in solid solution temperature. Figure $3 \mathrm{~b}$ shows the effect of the solid solution temperatures on tensile strength. As a result of the tensile tests tensile strength was $610 \mathrm{MPa}$ for the specimen treated at $465^{\circ} \mathrm{C}$, whereas the 

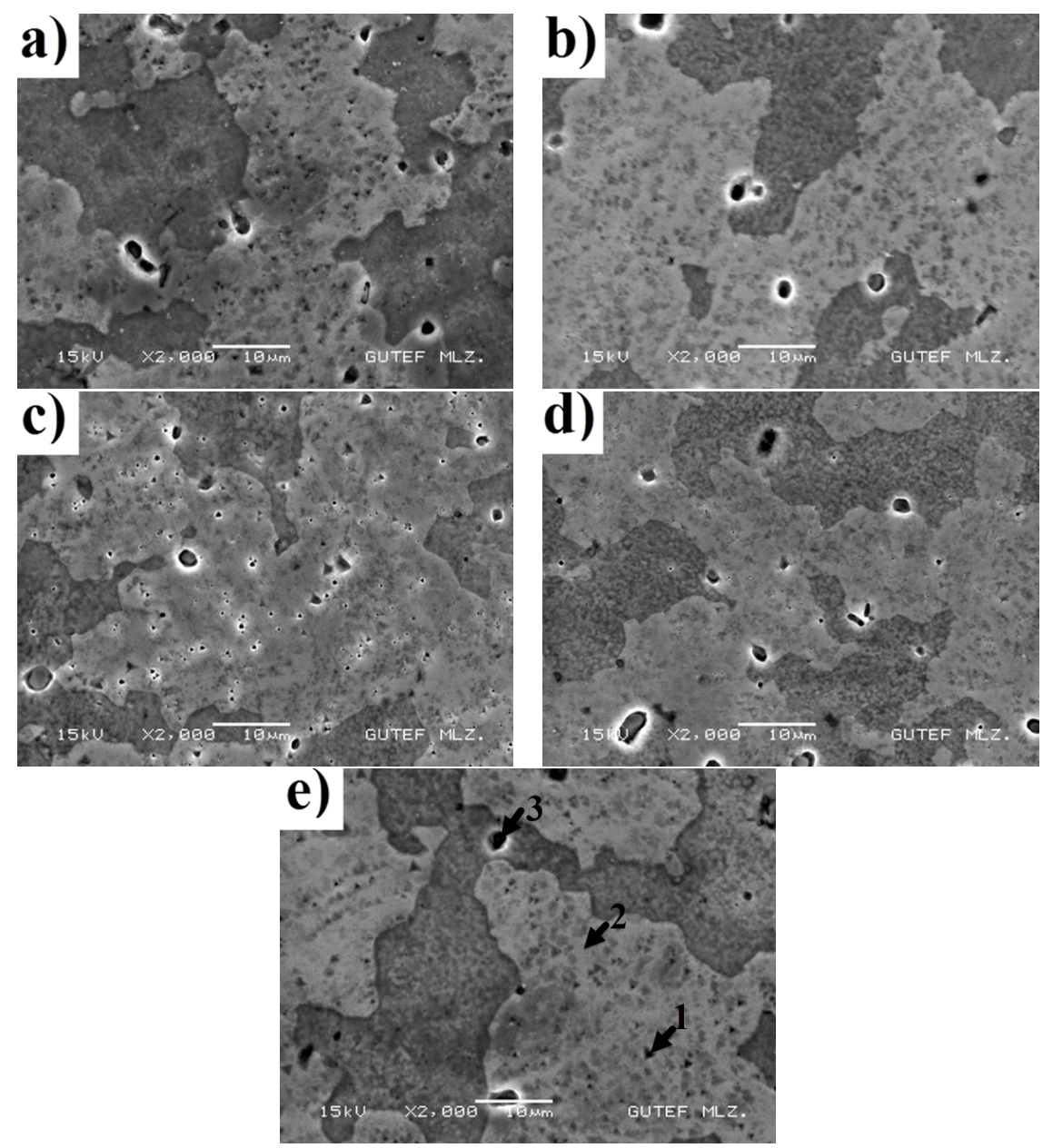

Figure 1: SEM images of the AA7075 alloy aged $120^{\circ} \mathrm{C}$ for 24 hours following solid solution at different temperatures of a) $465^{\circ} \mathrm{C}$ b) $470^{\circ} \mathrm{C}$ c) $475^{\circ} \mathrm{C}$ d) $482^{\circ} \mathrm{C}$ e) $485^{\circ} \mathrm{C}$.

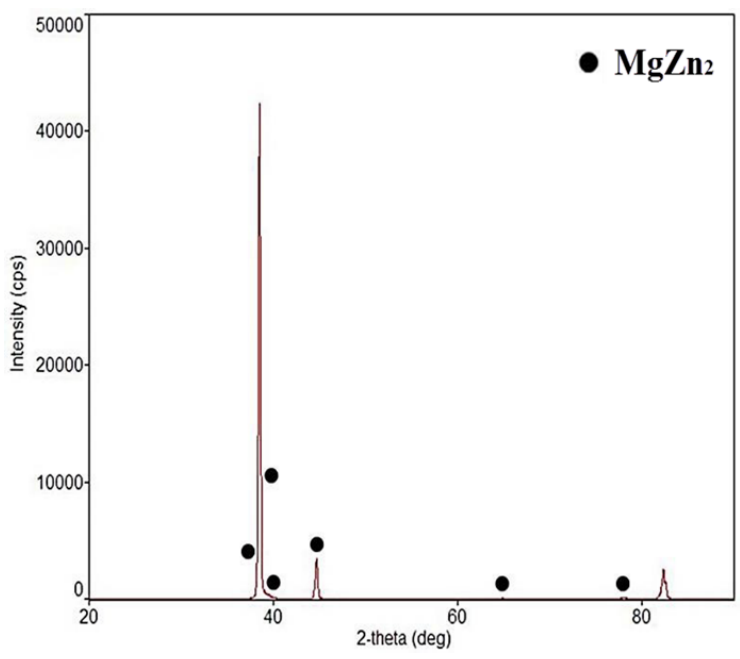

Figure 2: The XRD results of the AA7075 alloy after T6 heat treatment. highest applied to specimens solid solution treated at different temperatures followed by aging, it was seen that the increased solid solution temperature led to an increased in tensile strength. The lowest tensile strength was $632 \mathrm{MPa}$ for the specimen treated at $485^{\circ} \mathrm{C}$. The increase in the solid solution temperature causes compounds which form in the structure during the hardening of the alloy in an uncontrolled manner to further dissolve and the quenched at room temperature leads to more effective formation of the supersaturated solid solution structure. Thus, the supersaturated solid solutions in the structure which occur more effectively and the increased precipitate amount due to aging cause the strength of the material increase further. Mahathaninwong et al. [18] note that alloy compounds completely dissolve without forming brittle and coarse particles due to increased solid solution temperature, the quenched at room temperature leads to formation of compound and element precipitates in the rich solid solutions, and the strength of the alloy increases. Figure 4 shows the 

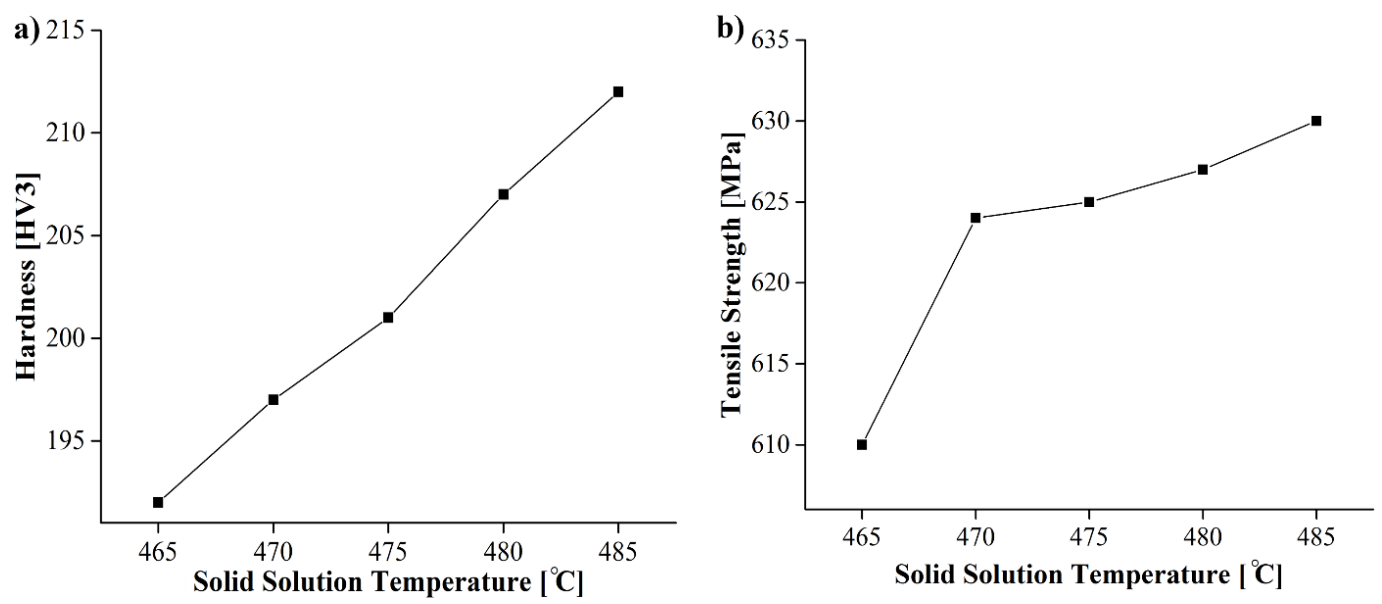

Figure 3: Hardness (a) and tensile strength (b) change of the AA7075 alloys after solid solution and age heat treatments.
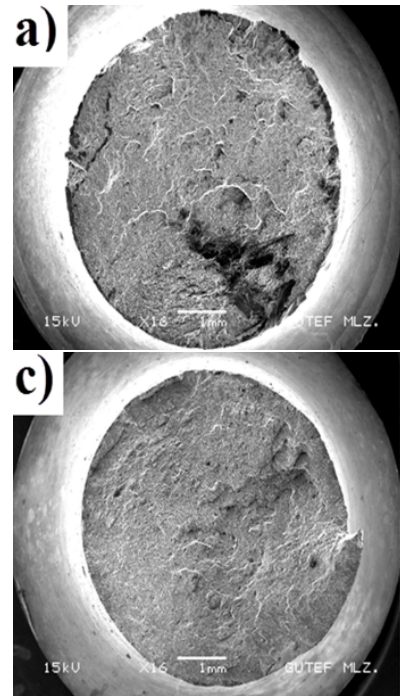
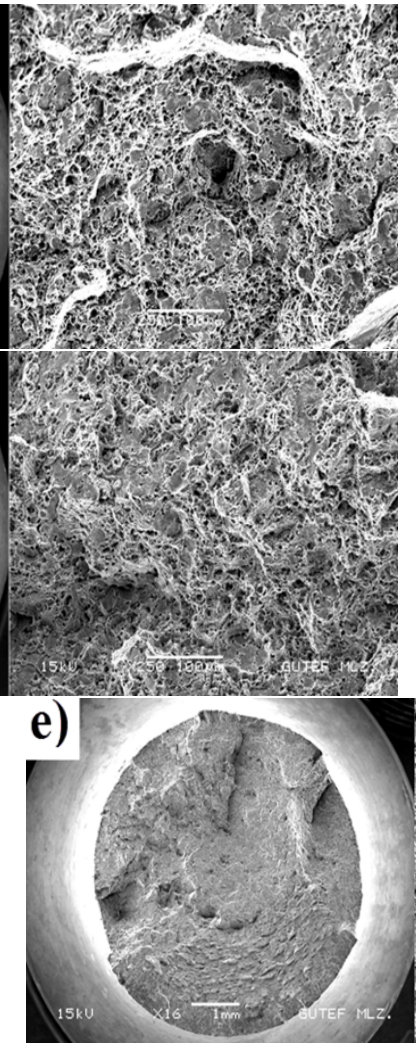
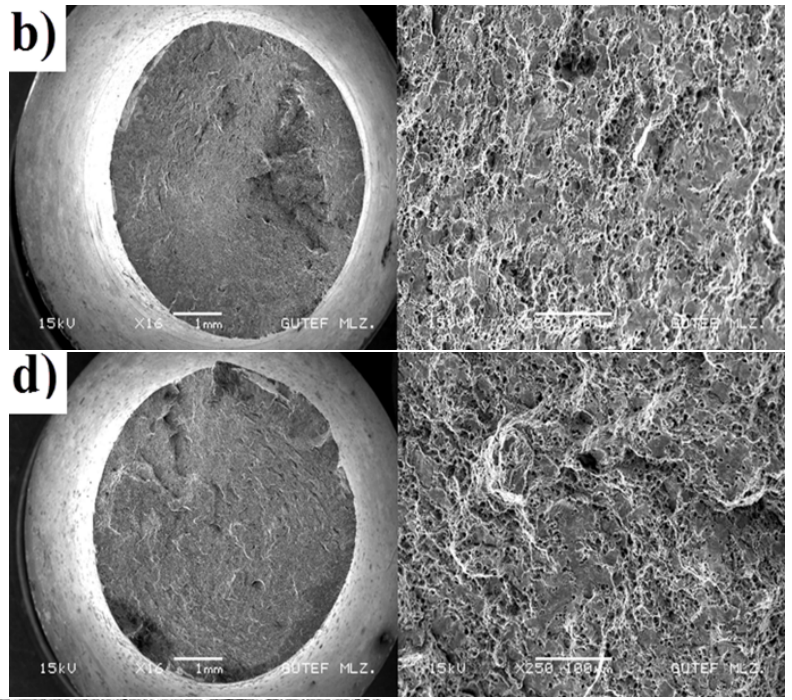

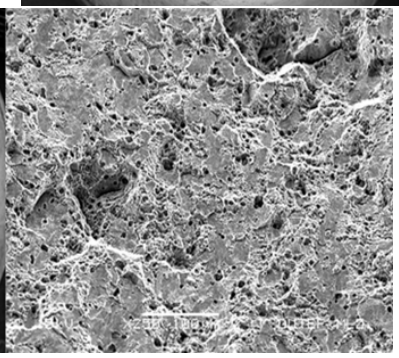

Figure 4: The fractured surface SEM images of the alloys after the tensile tests a) $465^{\circ} \mathrm{C}$ b) $470^{\circ} \mathrm{C}$ c) $475^{\circ} \mathrm{C}$ d) $482^{\circ} \mathrm{C}$ e) $485^{\circ} \mathrm{C}$.

fractured surface SEM images of the alloys, which were solid solution treated at different temperatures followed by aging, after the tensile test.

The fractured surface SEM examinations given in Figure 4 showed pores on the fracture surfaces. The fracture seems to have occurred due to small gaps between aluminum grains separated by grain boundaries joining together with the effect of tension applied to specimens. While there were some small gaps within the alloy, others were formed by dislocation and second phase precipitates formed in the structure due to aging. As seen in Figure 4, the mode of the fracture which occurred after the tensile test was ductile. This was evident from the presence of fine and round pores and large number of pits. The ductile fraction which occurred in the structure was supported by joining of small gaps, which led to formation of larger pits as seen in fractured surface images [11, 19]. 


\section{Conclusion}

The following results are obtained in the present study for the specimen solid solution treated at 5 different temperatures for 2 hours and then artificially aged at $120^{\circ} \mathrm{C}$ for 24 hours.

- It was found that the increased solid solution temperature led to formation of precipitates in the alloy's structure.

- The increased solid solution temperature led to an increase in the hardness of the alloy.

- In tensile tests, the maximum tensile strength was observed for the maximum solid solution temperature.

\section{References}

[1] Z. X. Wang, Y. A. Zhang, B. H. Zhu, H. W. Liu, F. Wang, and B. G. Xiong, Trans. Nonferrous Met. Soc. China, 16 (2006) 808-812.

[2] H. Aydın, A. Bayram, M. T. Yıldırım, and K. Yigit, Mater. Sci. (Medziagotyra), 16(4) (2010) 311-319.

[3] R. H. Oskouei and R. N. Ibrahim, Mater. Sci. Eng., A, 528 (2011) 1527-1533.

[4] P. Cavaliere and F. Panella, J. Mater. Process. Technol., 206 (2008) 249-255.
[5] J. F. Li, Z. W. Peng, C. X. Li, Z. G. Jia, W. J. Chen, and Z. Q. Zheng, Trans. Nonferrous Met. Soc. China, 18 (2008) 755-762;

[6] P. S. De, R. S. Mishra, and C. B. Smith, Scripta Mater., 60 (2009) 500-503.

[7] Y. Xue, H. El-Kadiri, M. F. Horstemeyer, J. B. Jordon, and H. Weiland, Acta Mater., 55 (2007) 1975-1984.

[8] K. S. Al-Rubaie, E. K. L. Barroso and L. B. Godefroid, Mater. Sci. Eng. A, 486 (2008) 585-595.

[9] D. Özyürek, R. Yılmaz, and E. Kibar, J. Fac. Eng. Arc. of Gazi University, 27(1) (2012) 193-203.

[10] R. Yılmaz, D. Özyürek, and E. Kibar, J. Fac. Eng. Arc. of Gazi University, 27(2) (2012) 429-438.

[11] A. Fakioglu, D. Özyürek and R. Yılmaz, High Temp. Mater. Processes (London), 32 (4) (2013) 345-351.

[12] A. Kalyon and D. Özyürek, Acta Phys. Pol., A, 131(1) (2017) 150152.

[13] R. Clark, B. Coughran, I. Traina, A. Hernandez, T. Scheck, C. Etuk, et al., Eng. Fail. Analy., 12(4) (2005) 520-526.

[14] M. Song and K. Chen, J. Mater. Sci., 43(15) (2008) 5265-5273.

[15] A. Somoza and A. Dupasquier, J. Mater. Proces. Technol., 135(1) (2003) 83-90.

[16] N. Kamp, I. Sinclair, and M.J. Starink, Metall and Mat Trans A, 33(4) (2002) 1125-1136.

[17] A. Abolhasani, A. Zarei-Hanzaki, H. R. Abedin, and M. R. Rokni, Mater. Des., 34 (2012) 631-636.

[18] N. Mahathaninwong, T. Plookphol, J. Wannasin, and S. Wisutmethangoon, Mater. Sci. Eng. A, 532 (2012) 91-99.

[19] A. Fakioglu and D. Özyürek, Mater. Test., 56(7-8) (2014) 575-582. 